\title{
Balanced Innovative Development of Energy Enterprises Under the Conditions of Digitalization as a Factor of Economic Security of Russia
}

\author{
Oksana Kiseleva \\ Department of Economic Security and Innovation \\ Management \\ Yuri Gagarin State Technical University of Saratov \\ Saratov. Russian Federation \\ oksana@briik.ru
}

Alexandra Kulbyakina

Department of Thermal and Nuclear Power Engineering named after A. I. Andryushchenko

Yuri Gagarin State Technical University of Saratov

Saratov. Russian Federation

lenkova_av@rambler.ru

\author{
Elena Oskina \\ Department of Economic Security and Innovation \\ Management \\ Yuri Gagarin State Technical University of Saratov \\ Saratov. Russian Federation \\ simmi72@yandex.ru \\ Olga Sysoeva \\ Department of Economic Security and Innovation \\ Management \\ Yuri Gagarin State Technical University of Saratov \\ Saratov. Russian Federation \\ ovzaytseva@mail.ru
}

\begin{abstract}
The article deals with the issues of digitalization of energy enterprises as representatives of one of the most important sectors of the Russian economy, which determines the possibility of developing other spheres of the national economy in order to ensure the economic security of the Russian Federation.

As a priority direction of digitalization, the "digitalization" of innovation activity is justified, which allows to accelerate the pace of our country's innovation breakthrough and create favorable conditions for security in the economic sphere and at the national level. Based on the analysis of the existing experience of digitalization of energy enterprises, it is determined that there are currently a number of problems that prevent the effective implementation of measures in accordance with the developed program of digitalization of energy enterprises and their innovative activities.

The low level of applied management methods, technologies and tools used for digital transformation of innovative activities of representatives of the energy industry is considered to be one of these problems. Organizational and managerial innovations are defined as a tool for bringing the applied management technologies and management methods to the necessary level.

It is proved that the effective digital transformation of energy enterprises is possible only with the simultaneous application of innovations in the technological sphere and non-technological forms of innovation, which will contribute to creating favorable conditions for ongoing changes, complementarity and complementarity of transformation processes in order to obtain a synergistic effect that leads to a stronger positive innovative result. It is proposed to implement digitalization for the purposes of innovative development on the principles of balance, which
\end{abstract}

digital technologies should find simultaneous application in the technological and managerial sphere.

The implementation of changes in the proposed version will ensure the successful innovative development of energy enterprises on the basis of digitalization, which will contribute to the formation of the necessary conditions for economic security.

Keywords: economic security, digitalization, energy enterprises, management system, balanced innovative development

\section{INTRODUCTION}

In the context of events taking place in the world politics, the problem of ensuring economic security is particularly pressing in our country, which directly determines the national economy's stability and dynamics of development, its efficiency and competitiveness among other competitive of empyrean in the internal and embracing markets

The state of economic security ensures the creation of favorable conditions for the effective functioning of both individual economic entities and the state in tote. In this context, issues related to the search for solutions, which implementation lead to the creation of such conditions, become particularly relevant.

At the same time, there are several drivers of economic security in our country that are actively developed and supported at the state level. The first of them, which has been a priority for more than ten years, is the innovative 
development of domestic enterprises, which target parameters are defined in the strategy of innovative development of the Russian Federation for the period up to 2020. The second one which received a significant boost after the 2014 crisis, is the development of priority sectors of the national economy, primarily representatives of the energy sector as the flagship of economic development, which is reflected in Russia's Energy strategy for the period up to 2030. The third, which is becoming more and more relevant - is the transition to digital technologies, or digitalization, of Russian enterprises. Digitalization is declared to be the main course in the coming years by the Decree of the President of Russia No. 204 of 7.05.2018 "on national goals and strategic objectives of the development of the Russian Federation for the period up to 2024".

Aspects of development within these drivers are widely covered in the works of modern researchers. At the same time, as a rule, there is the following division of the issues taken into consideration: digitalization of innovative processes of enterprises $[1,2,3,4]$, digital transformation of energy enterprises $[5,6,7,8]$, innovative development of representatives of the heat and power complex $[9,10,11,12,13]$. At the same time, the issue of digitalization of innovative processes of energy enterprises is not taken into consideration.

According to the authors, the most promising avenue for ensuring the Russian Federation economic security is to consider the synergy of the main drivers of development, expressed in the digitalization of innovative activities of energy enterprises, which creates favorable conditions for development not only for the energy sector but also for representatives of other industries.

\section{ANALYSiS OF THE MAIN TRENDS IN DigitalizATION OF ENERGY COMPANIES}

The digital economic emergence means the shift to a new stage of social economic development, including the system of information technologies and their widespread introduction. Digitalization is aimed at performance improvement of the management quality and such fields as information and communication technologies, trading, banking sector, transport, and also offers the challenge to improve quality of people's living [5]. Taking into account the importance of the energy complex for the Russian economy and the effect that the results of digital transformation provide (first of all, reducing costs and improving the efficiency of production processes), focusing on this industry in terms of digitalization is quite justified. Currently, the Digital energy project is being actively implemented in Russia, the main goal of which is the digital transformation of the fuel and energy sector and the introduction of innovative developments. The main projects of digitalization in the energy sector are automation of transmission and distribution of electricity, equipment monitoring, enhancement of safety, improving the quality of energy supply to consumers, the introduction of a risk-oriented approach, the creation of new intelligent ecosystems, the introduction of digital substations and "smart networks". The program of creating a single digital space of the Russian industry as a result of a the joint operation of the Ministry of
Industry and Trade of the Russian Federation and Siemens is considered to be a pioneering collaboration in the sphere of energy sector digitalization. The complex implementation of digital technologies in all stages and production levels is planned. This is due to the fact that Russian energy companies are the drivers of promoting economic upturn and social modernization in the country.

However, nowadays the actual results of digitalization do not correspond to the established targets, as evidenced by expert estimates [14]. According to the business digitalization index, Russia is on the same level as Poland and Greece (31 out of 50), in terms of the intensity of digital technology use, Russia ranks 26th out of 32 countries surveyed, and the digitalization of the energy complex is 13 points behind the EU countries.

However, the significant limitation of digitalization's transition is technological inferiority of many spheres, caused by the lack of bankroll, the low level of innovations and underdeveloped financial market. In the ranking of the World Economic Forum, Russia ranks $41 \mathrm{st}$ in terms of digital economy readiness and 38th in terms of economic and innovative results in the usage of digital technologies. Currently, the contribution of the digital economy to the country's GDP fluctuates in the range of 1.2-4.5\% [15].

Despite the "loud" statements of the Russian energy Minister Alexey Texler that the Russian heat and power complex is in an absolute trend with global trends, accompanied by the simultaneous launch of numerous projects for the digital transformation of production processes in the industry, as experts point out, digital transformation in Russia stands still, and in order to maintain our country's competitive position in the world market, according to Bloomberg estimates, the transition to digital technologies must be carried out in the period up to 2025. Accordingly, this determines the need to intensify the processes of digitalization, and this opportunity is provided by the transfer of "digital" innovation, which, in turn, is aimed at solving problems that hinder the implementation of digital technologies.

\section{Digitalization AND INNOVATIVE DEVELOPMENT}

Thus, the results obtained indicate that there is currently insufficient elaboration of issues that allow for effective digitalization of not only the current activities of energy enterprises, but also their innovative activities. The most important value of energy enterprises transition to "digital rails" is the creation of conductive conditions for their innovative development. The digital technologies usage helps to optimize the development processes of information exchange and implementation of innovative ideas, search for solutions and interaction of innovative project participants. In addition, the introduction of digitalization, the evidence of practice shows, provides growth of eventual positive outcome of activity, expressed in profit mark-up, cost saving, improving the product and services quality. As a result, the company acquires an additional source of financing for its innovation activities. 
methods aimed at developing and implementing effective management solutions.

Confirmation of the demand for organizational and managerial innovations for energy companies is the results of research on innovative activities (PJSC "Hydro WGC", PJSC "Stock Company G. M. Khrzhizhanovsky Power Engineering Institute", PJSC "IDGC of Centre", PJSC RDC Electric Power, PJSC "WGC4"), reflecting the high demand for them (in $60 \%$ of cases) [13]. Moreover, the reasons for this need are the need to implement new strategic goals and the emergence of a complex management problem that requires an innovative approach to solving it. This is exactly what applies to the situation of digitalization of energy enterprises.

Innovative digitalization will not yield the intended effect if there is a gap between the technological sphere and the managerial system, which will determine the slowdown in the processes of transformation, transmission and data processing. The whole enterprise should be in a closed information loop, projecting the necessary information on the innovative processes and functioning in general. Accordingly, in order to avoid such a gap, digitalization must take place in an integrated manner. At the same time, the main condition and principle of effective transition to digital technologies should be a balance that determines the dynamism, synchronicity, complementarity, complementarity of the data collection processes, transmission, processing and transformation between the technological and managerial spheres.

The balance of innovation projects of technicaltechnological and organizational-administrative sphere should be achieved, defined as the optimal ratio of simultaneously initiated innovative projects in the technical-technological and organizational-administrative sphere, based on the resource, structural, and functional security plan and the results expressed in achieving the targets of development and balance innovation processes and energy companies, expressed in the continuity, synchronization, resource allocation, dynamism, unified orientation of the development processes in the technical, technological, organizational and managerial spheres, and convergence of their outputs to a common development goal. Only in this case a positive result of innovative digitalization will be achieved, supplemented by a synergistic effect due to the transition to a single information complex of all existing systems of the energy enterprise.

\section{CONCLUSIONS}

Thus, the innovative digitalization of energy enterprises, implemented on the principles of balance, will create the necessary conditions for their innovative development, which will contribute to improving economic security both at the level of individual enterprises and at the level of our state as a whole.

Moreover, in our opinion, further research in this direction will allow us to find solutions to other problems that accompany the process of digitalization of enterprises in both energy and other sectors of the national economy, such as generating and accumulating funds for development, reducing the risks associated with changes, and optimizing the processes of developing and implementing innovations. 
Sources", AIP Conference Proceedings, 2019 [Electronic resource]. Available at: https://aip.scitation.org/doi/10.1063/1.5122066.

\section{References}

[1] A.V. Cheper and O.H. Cheper, "Development of special principles of business innovation activities mechanism", Financial and credit activity-problems of theory and practice, vol. 3, no. 30, pp. 206-214, 2019.

[2] A.V. Kuchumov, "Digital technologies as a factor in the innovative development of the agro-industrial complex to ensure the food security of the country", Proceedings of the 1st International Scientific Conference "Modern Management Trends and the Digital Economy: from Regional Development to Global Economic Growth, pp. 28-35, 2019.

[3] S.E. Terentyev, O.V. Lazko, and A.V. Belokopytov, "Organizational and economic aspects of the implementation of digital technologies in the innovative development of dairy cattle breeding", Proceedings of the 1st International Scientific Conference, Modern Management Trends and the Digital Economy: from Regional Development to Global Economic Growthm, pp. 46-51, 2019.

[4] E.N. Bykovskaya, YU.N. Kafiyatullina, and G.P. Harchilava, "Current trends in the digitalization of the innovation process", Management, no. 1 (19), pp. 38-43, 2018.

[5] I.B. Teslenko, N.V. Muravyova, O.V. Digilina, I.I. Saveliev, and M.V. Khripunova, "New Interaction Models in Digitalization: The Sharing Economy", Proceedings book "Digital Economy: Complexity and Variety Vs. Rationality", pp. 623-630, 2019.

[6] Ye.D. Burda, I.O. Volkova, E.V. Gavrikova, and A.V. Kosygina, "Digitalization and ways for the development of the electric energy industry with the participation of consumers: new challenges for shaping the investment climate", Journal of Siberian Federal University Humanities \& Social Scences, no. 12 (4), pp. 545-564, 2019. DOI: 10.17516/1997-1370-0408.

[7] T. Mitrova, A. Galkina, and V. Kulagin, "The transformation of Russia's gas export policy in Europe", Proceedings of Institution of Civil Engineers: Energy, no. 1, pp. 30-40, 2015.

[8] L.M. Velichkina and L.P. Gossen, "The most significant trends in modern issues of rational use of oil and gas resources of Russia", Oil refining and petrochemicals. Scientific and technological achievements and best practices, no. 10, pp. 31-40, 2015.

[9] A.V. Kulbyakina, N.A. Ozerov, and P.A. Batrakov, "Efficiency Evaluation of Oil and Gas Processing Plants Internal Power Supply
[10] L. Boqiang and Z. Junpeng, "Determinants of renewable energy technological innovation in China under $\mathrm{CO} 2$ emissions constraint", Journal of environmental management, no. 247, pp. 662-671, 2019.

[11] S. Al Saqoor, A. Alahmer, F. Al Quran, A. Andruszkiewicz, K. Kubas, P. Regucki, and W. Wędrychowicz, "Numerical modeling for the retrofit of the hydraulic cooling subsystems in operating power plant", Thermal Engineering, vol. 64, no. 8, pp. 551-558, 2017.

[12] E.K. Arakelyan, A.V. Andriushin, S.Y. Burtsev, K.A. Andriushin, and S.R. Hurshudyan, "Methodology for consideration of specific features of combined-cycle plants with the optimal sharing of the thermal and the electric loads at combined heat power plants with equipment of a complex configuration", Thermal Engineering, vol. 62, no. 5, pp. 335$340,2015$. innovation management system in energy companies", Bulletin of the Chuvash University, no. 3, pp. 233-240, 2013.

[14] G.I. Abdrahmanova, K.O. Vishnevskij, and L.M. Gohberg, "Digital Economy Indicators: 2019: Statistical Digest", National Research University "High School of Economics", 248 p., 2019.

[15] O.A. Romanova and A.O. Ponomareva, "Theoretical, institutional and ethical foundations for the implementation of modern industrial policy. Part I", The economy of the region, vol. 15, no. 1, pp. 13-28, 2019.

[16] G.A. Agafitei and S. Avasilcai, "A case study on open innovation on Procter \& Gamble. Part I: Innovation strategy over years", Modern Technologies in Industrial Engineering, 2015. DOI: 10.1088/1757899X/95/1/012149.

[17] F. Gault, "User Innovation in the Digital Economy", Foresight and STI Governance, vol. 13, no. 3, pp. 6-12, 2019. DOI: 10.17323/25002597.2019.3.6.12.

[18] V.S. Zharov, "Digitalization of the technological development management process of the Russian economy", Proceedings of the 1st International Scientific Conference, Modern Management Trends and the Digital Economy: from Regional Development to Global Economic Growth, pp. 273-276, 2019.

[19] E. Ustyugova, "Digitalization of industry as a tool to improve production efficiency", Best practices and new solutions [Electronic resource]. Available at: https://www.kommersant.ru/doc/3744965 (Accessed: 10.12.2019).

[20] M.N. Rudenko and YU.I. Gribanov, "Digitalization and Service Trends in the Economy", Theory and practice of service: economics, social sphere, technology, no. 2 (40), pp. 5-8, 2019.
[13] O.V. Fedorov, N.V. Golubcov, and L.G. Efremov, "Formation of an 